\title{
A Validated LC-MS/MS Method for the Estimation of Apixaban in Human Plasma
}

\author{
Mirza Layeeq Ahmed Baig ${ }^{1}$, Syed Ayaz Ali $^{2 *}$ \\ ${ }^{1}$ Research scholar, Faculty of Pharmacy, Pacific Academy of Higher Education and Research University, Udaipur, Rajasthan, India . \\ ${ }^{2}$ Department of Pharmacology, Y.B. Chavan College of Pharmacy, Dr. Rafiq Zakaria Campus, Aurangabad, Maharashtra, India.
}

\section{ARTICLE INFO}

Article history:

Received on: 04/03/2017

Accepted on: 14/04/2017

Available online: $30 / 04 / 2017$

Key words:

LC-MS/MS, Factor Xa

inhibitor, Antithrombotic,

Apixaban.

\begin{abstract}
A high performance liquid chromatography mass spectrometric method for the estimation of apixaban in human plasma has been developed and validated using apixaban ${ }^{13} \mathrm{CD}_{3}$ as an internal standard (IS). The extraction of analyte and IS was accomplished by liquid-liquid extraction technique. The method has been validated over a concentration range of $1.00 \mathrm{ng} \mathrm{mL}^{-1}$ to $301.52 \mathrm{ng} \mathrm{mL}^{-1}$. Chromatographic separations was achieved using Thermo Beta basic- $8,100 \mathrm{~mm} \times 4.6 \mathrm{~mm}, 5 \mu$, column eluted at flow rate of $1.0 \mathrm{~mL}$ minute ${ }^{-1}$ with $1: 1$ splitted post column with mobile phase Acetonitrile: Ammonium formate buffer $\mathrm{pH} 4.2(70: 30 \mathrm{v} / \mathrm{v})$. The overall run time of method was about 3.0 min. with elution times of apixaban and its internal standard apixaban ${ }^{13} \mathrm{CD}_{3}$ at around $1.2 \mathrm{~min}$. The multiple reaction monitoring transitions were set at $460.2>443.2(\mathrm{~m} / \mathrm{z})$ and $464.2>447.4(\mathrm{~m} / \mathrm{z})$ for apixaban and apixaban ${ }^{13} \mathrm{CD}_{3}$ respectively. The calibration curves were linear $\left(\mathrm{r}^{2} \geq 0.99\right)$ over the range of 1.0 $301.52 \mathrm{ng} \mathrm{mL}^{-1}$ with lower limit of quantitation validated at $1.0 \mathrm{ng} \mathrm{mL}^{-1}$. Extraction recoveries were $>98 \%$ for both apixaban and its stable labeled IS apixaban ${ }^{13} \mathrm{CD}_{3}$. The within run and between run precisions were within $0.70 \%-6.98 \%$, while accuracy ranged from 89.2 to $107.2 \%$.
\end{abstract}

\section{INTRODUCTION}

Apixaban is a potent, oral, reversible, direct and highly selective active site inhibitor of Factor-Xa. It does not require antithrombin III for antithrombotic activity. Apixaban inhibits free and clot-bound Factor-Xa, and prothrombinase activity. Activation of Factor-X to Factor-Xa (FXa) via the intrinsic and extrinsic pathway plays a central role in the cascade of blood coagulation. Apixaban has no direct effects on platelet aggregation, but indirectly inhibits platelet aggregation induced by thrombin. By inhibiting Factor-Xa, apixaban prevents thrombin generation and thrombus development (Mueck et al.,

* Corresponding Author

Dr. Syed Ayaz Ali, M.Pharm; Ph.D (Pharmacology) Associate Professor \& Head Department of Pharmacology, Y.B.Chavan College of Pharmacy Dr. Rafiq Zakaria Campus, Rauza Baugh, Aurangabad-431001, (M.S)

India.E-mail: ayazpharm @ gmail.com, Mobile No.: +919960883737
2011; Mueck et al., 2013; Matchar et al., 2002; Gadisseur et al., 2004; Shenker et al., 2012). Preclinical studies of apixaban in animal models have demonstrated antithrombotic efficacy in the prevention of arterial and venous thrombosis at doses that preserved hemostasis. There is a clear correlation between plasma apixaban concentration and degree of anticoagulant effect. The maximum effect of apixaban on pharmacodynamic parameters occurs at the same time as Cmax. Apixaban is extensively metabolized via CYP3A4 and is a substrate for P-glycoprotein (Barrett et al., 2010; Wang et al., 2010; Wang et al., 2006). It has multiple routes of elimination. Approximately 50-55\% of apixaban is eliminated in the feces and $20-25 \%$ is excreted in the urine. Earlier publications have described methods for determination of apixaban in biological matrix using liquid chromatography tandem mass spectrometry (LC-MS/MS) methods (Zhang et al., 2016; Baldelli et al., 2016; Noguez et al., 2016; Blaich et al., 2015; Schmitz et al., 2014; Gous et al., 2014; Delavenne et al., 2013). Many places UPLC have been used for separation. 
In this study, we attempted to develop a simple and rapid method for the determination of apixaban in human plasma using a HPLC MS/MS method to evaluate the oral pharmacokinetics of apixaban tablets. Compared with previous methods, the present method has the following advantages: less plasma was required, sample preparation was simpler, and the analysis time was shorter using normal HPLC conditions making it suitable to analyze large number of samples.

\section{EXPERIMENT}

\section{Chemicals and reagents}

The reagents/materials used during analysis include ammonium formate (AR grade), acetonitrile (HPLC grade), orthophosphoric acid (HPLC grade), formic acid (HPLC grade), methyl tert. butyl ether (HPLC grade), methanol (HPLC grade), ethyl acetate (HPLC grade) and water (Milli-Q/HPLC grade). Apixaban and apixaban ${ }^{13} \mathrm{CD}_{3}$ with purity > 98\% were purchased from Simson Pharma, Mumbai, (Fig.1a and1b). Blank human $\mathrm{K}_{2}$ EDTA plasma was purchased from blood bank.

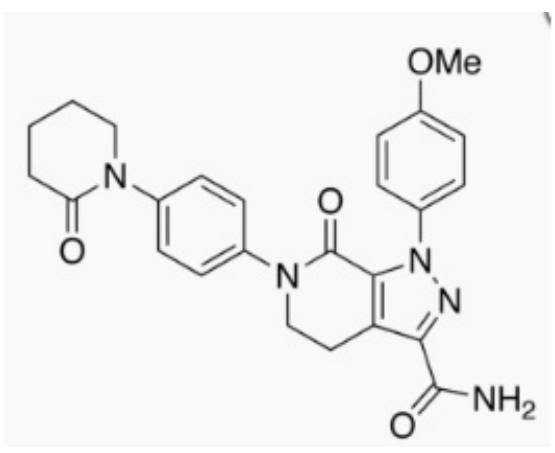

Fig. 1a: Chemical structure of Apixaban.

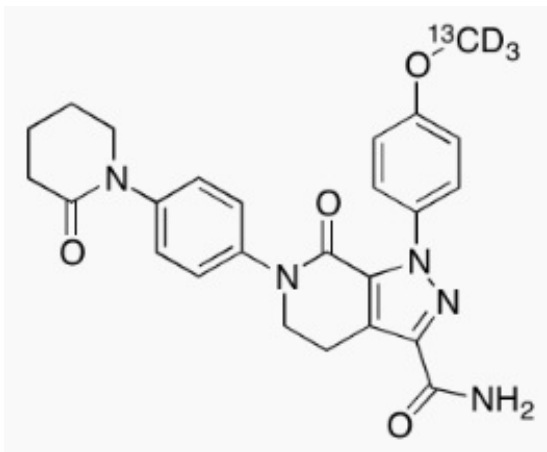

Fig. 1b: Chemical structure of Apixaban ${ }^{13} \mathrm{CD}_{3}$.

\section{Apixaban stock solution}

Approximately $5 \mathrm{mg}$ of apixaban was weighed and transferred to $5 \mathrm{~mL}$ volumetric flask. It was dissolved and made up to the mark with HPLC grade methanol to make approximately 1.0 $\mathrm{mg} \mathrm{mL}^{-1}$ stock solution. This stock solution was transferred in a reagent bottle with appropriate label and stored at $2^{\circ} \mathrm{C}$ to $8^{\circ} \mathrm{C}$. This solution was used within 8 days from the date of preparation.
Further dilutions of apixaban were prepared in Methanol: MilliQ water, $50: 50 \mathrm{v} / \mathrm{v}$ for spiking into plasma.

\section{Apixaban 13CD3 (IS) stock solution}

Approximately $2 \mathrm{mg}$ of apixaban ${ }^{13} \mathrm{CD}_{3}$ was weighed and transferred to $2 \mathrm{~mL}$ volumetric flask. It was dissolved and made up to the mark with HPLC grade methanol to make approximately 1.0 $\mathrm{mg} \mathrm{mL}^{-1}$ stock solution. This stock solution was transferred in a reagent bottle with appropriate label and stored at $2^{\circ} \mathrm{C}$ to $8^{\circ} \mathrm{C}$. This solution was used within 8 days from the date of preparation. Further stock dilutions of apixaban ${ }^{13} \mathrm{CD}_{3}$ was prepared in Methanol: MilliQ water, 50:50 v/v solution.

\section{Ammonium formate buffer (pH $4.2 \pm 0.05$ )}

About $126.12 \mathrm{mg}$ of ammonium formate was weighted and transferred into $1000 \mathrm{~mL}$ volumetric flask. It was dissolved with Milli-Q water/HPLC grade water and volume was made up to the mark. It was then sonicated in an ultrasonicator for 5 to 10 minutes. The $\mathrm{pH}$ was adjusted to $(4.2 \pm 0.05)$ with diluted formic acid. The buffer was used within 4 days from the date of preparation.

\section{Rinsing Solution}

A mixture of acetonitrile and Milli-Q water was prepared in the volume ratio of $70: 30 \mathrm{v} / \mathrm{v}$ as rinsing solution. It was sonicated in an ultrasonicator for 5 to 10 minutes. The solution was used for auto sampler rinsing to avoid carryover.

\section{Mobile Phase}

A mixture of acetonitrile and ammonium formate buffer $\mathrm{pH}(4.2 \pm 0.05)$ was prepared in the volume ratio of $70: 30 \mathrm{v} / \mathrm{v}$ as mobile phase. It was sonicated in an ultrasonicator for 5 to 10 minutes. This was used within 4 days from the date of preparation.

\section{Calibration Curve Standards and Quality Control Samples}

Calibration curve standards of apixaban concentrations ranging from $1.0 \mathrm{ng} \mathrm{mL} \mathrm{m}^{-1}$ to $301.52 \mathrm{ng} \mathrm{mL}^{-1}$ were prepared by spiking appropriate dilutions of working stock solution in pooled blank plasma having $\mathrm{K}_{2}$ EDTA as anticoagulant. The five levels of QC samples of apixaban concentrations ranging from $1.0 \mathrm{ng} \mathrm{mL}$ (LLOQ QC), $2.77 \mathrm{ng} \mathrm{mL}^{-1}$ (LQC), $61.58 \mathrm{ng} \mathrm{mL}^{-1}$ (M1QC), 123.16 $\mathrm{ng} \mathrm{mL} \mathrm{mL}^{-1}$ (MQC) and $246.31 \mathrm{ng} \mathrm{mL}^{-1}$ (HQC) were prepared by spiking appropriate dilutions of stock solution in pooled blank $\mathrm{K}_{2}$ EDTA plasma. Spiking solution was not used more than $5 \%$ of total plasma volume. These samples were stored in deep freezer below $-50^{\circ} \mathrm{C}$ until use.

\section{Plasma sample extraction}

The spiked plasma samples were retrieved from the deepfreezer and thawed in a water bath at room temperature. The samples were extracted using liquid-liquid extraction technique. The thawed samples were vortexed to ensure complete mixing of the contents. A $50 \mu \mathrm{L}$ of IS dilution mixture (approximately 800.0 
ng $\mathrm{mL}^{-1}$ of apixaban ${ }^{13} \mathrm{CD}_{3}$ ) was taken in prelabeled polypropylene tubes except in blank samples wherein $50 \mu \mathrm{L}$ of dilution solution was added to compensate. A $250 \mu \mathrm{L}$ of sample was added to it and vortexed. This was followed by addition of $250 \mu \mathrm{L}$ of orthophosphoric acid and $250 \mu \mathrm{L}$ of formic acid and vortexed again followed by addition of $2 \mathrm{~mL}$ organic solvent mixture of ethyl acetate and methyl tertiary butyl ether (MTBE) in ratio of 70:30 and further vortexed for about 5 minutes. It was centrifuged for 4 min at about $4090 \mathrm{rcf}$ maintained at temperature $5^{\circ} \mathrm{C}$. After centrifuge $1 \mathrm{~mL}$ of supernatant was taken out into prelabeled glass tubes. The supernatant was dried at $50^{\circ} \mathrm{C}$ under a stream of nitrogen. The dried residue was reconstituted with $0.5 \mathrm{~mL}$ of solution consisting of acetonitrile and MilliQ water in ratio of 70:30 and transferred into disposable autosampler glass vials. Samples was analysed on AB Sciex API 3000 LC-MS/MS system using Turbo ion spray in positive mode.

\section{Equipment and software}

Shimadzu HPLC equipped with dual pump, auto sampler and column oven. Mass spectrometer AB SCIEX API 3000 LCMS/MS and data acquisition system Software Analyst Version 1.6.2 were used for the quantitative determination. The chromatograms were acquired using software Analyst version 1.6.2. The slopes, intercepts and goodness of fit were determined by linear regression analysis using the ratios of analyte/IS peak areas of the calibration curve standards. A weighting factor of $1 / \mathrm{x}^{2}$ (1/ concentration $^{2}$ ) was used in the calculation of the linear regression line and the concentrations of QC samples were calculated.

\section{Chromatographic Conditions}

Analytes were separated on a Thermo Beta basic- 8, 100 $\mathrm{mm} \times 4.6 \mathrm{~mm}, 5 \mu$, column maintained at temperature of $40^{\circ} \mathrm{C}$. An isocratic flow-rate of $1.0 \mathrm{~mL}$ minute $^{-1}$ with $1: 1$ splitted post column with mobile phase Acetonitrile: Ammonium formate buffer $(70: 30 \mathrm{v} / \mathrm{v})$ was used for chromatographic separation. The $\mathrm{pH}$ of ammonium formate buffer was adjusted to $(4.2 \pm 0.05)$ with diluted formic acid. Following $10 \mu \mathrm{L}$ injection analytes were separated. The overall run time was $3.0 \mathrm{~min}$. A mixture of acetonitrile and Milli-Q water in the volume ratio of 70:30 was used as needle wash solution to avoid carry over between two injections.

\section{Mass Spectrometry}

Mass spectrometric detection was performed on an Applied Biosystems Sciex (Concord, Ontario, Canada) API 3000 triple quadrupole mass spectrometer equipped with an electrospray ionization (ESI) interface. ESI ionization was performed in the positive ion mode. The tandem mass spectrometer was operated at unit resolution in the selected reaction monitoring mode (SRM), The multiple reaction monitoring transitions were set at $460.2>$ $443.2(\mathrm{~m} / \mathrm{z})$ and $464.2>447.4(\mathrm{~m} / \mathrm{z})$ for apixaban and apixaban ${ }^{13} \mathrm{CD}_{3}$ respectively (Fig. $2 \mathrm{a}, \mathrm{b}, \mathrm{c}, \mathrm{d}$ ).

The mass spectrometric conditions were optimized for apixaban and apixaban ${ }^{13} \mathrm{CD}_{3}$ by continuous infusion of the standard solution at the rate of $10 \mu \mathrm{L} \min ^{-1}$ using a Harvard infusion pump. The ion source temperature was maintained at $550^{\circ} \mathrm{C}$.

The ion spray voltage was set at $5500 \mathrm{~V}$. The curtain gas (CUR) was set at 6 psi and the collision gas (CAD) at 8 psi. The optimal collision energy (CE) was $35 \mathrm{~V}$. The following parameters of ion path were used as the most favorable ones: declustering potential (DP) at $50 \mathrm{~V}$ and entrance potential (EP) at $10 \mathrm{~V}$. Focusing potential (FP) was maintained at 120V.The quantification was performed via peak area ratio. Data acquisition and processing were accomplished using the Applied Biosystems Analyst version 1.6.2 software. Calibration curves were generated using peak area ratios of the components to internal standards versus the known concentrations with a linear regression equation of $1 /$ concentration $^{2}$.

$$
\mathrm{y}=\mathrm{mx}+\mathrm{b}
$$

Where, $y=$ peak area ratio of apixaban to apixaban ${ }^{13} \mathrm{CD}_{3}$ (IS), $\mathrm{m}=$ slope of the calibration curve, $\mathrm{x}=$ concentration of apixaban in $\mathrm{ng} \mathrm{mL}^{-1}, \mathrm{~b}=\mathrm{y}$-axis intercept of the calibration curve.

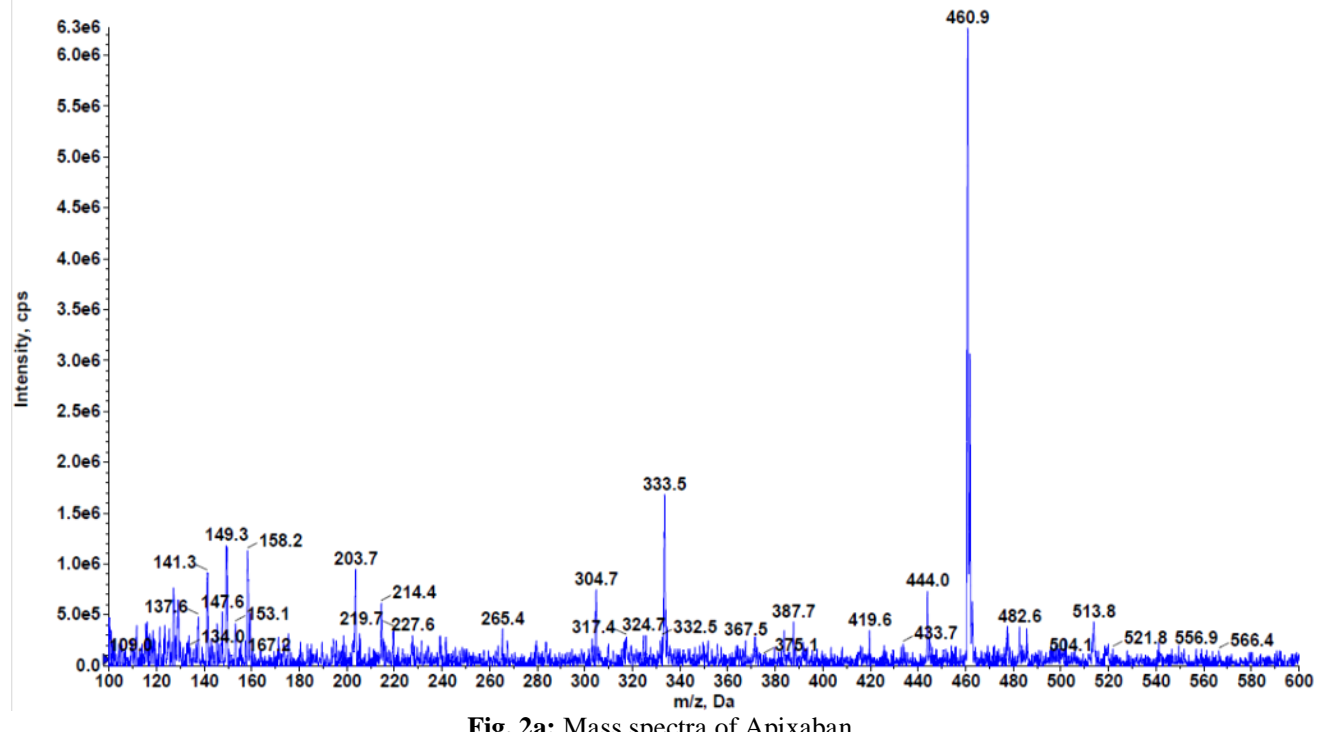

Fig. 2a: Mass spectra of Apixaban. 


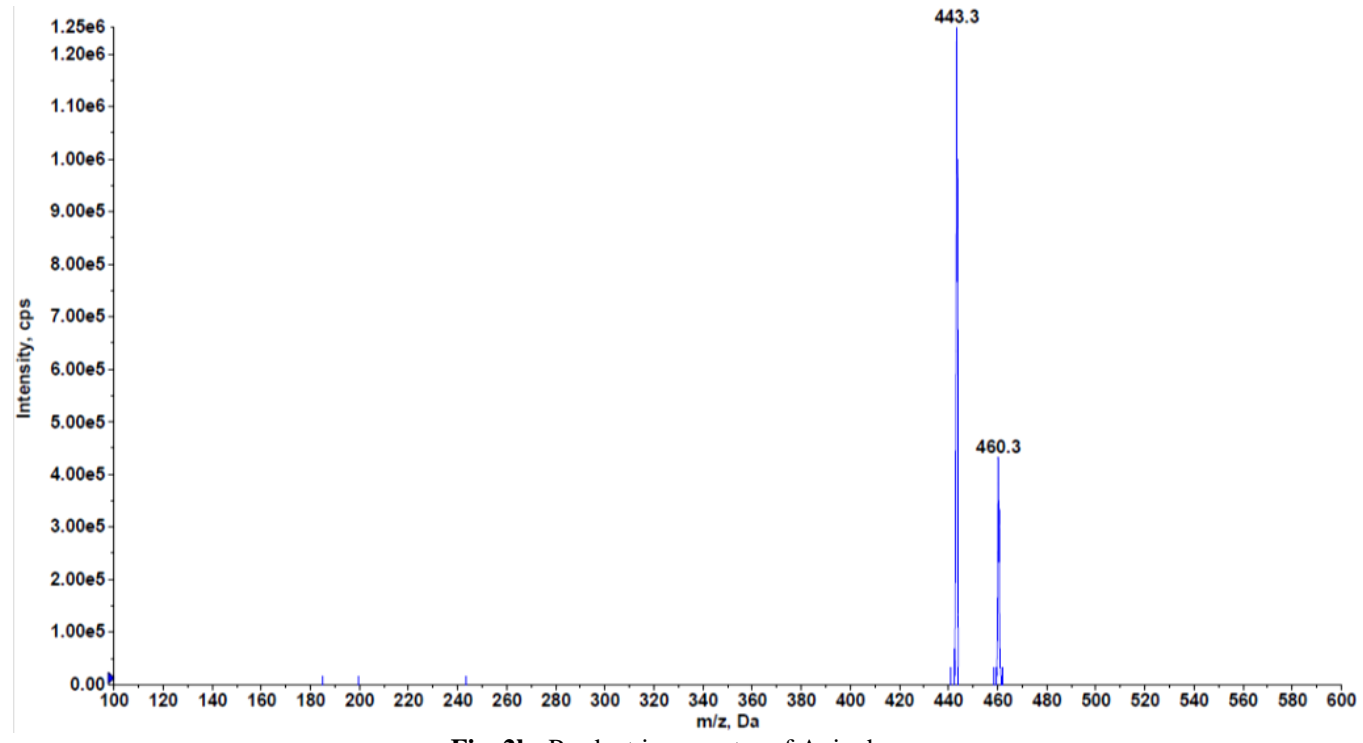

Fig. 2b: Product ion spectra of Apixaban.

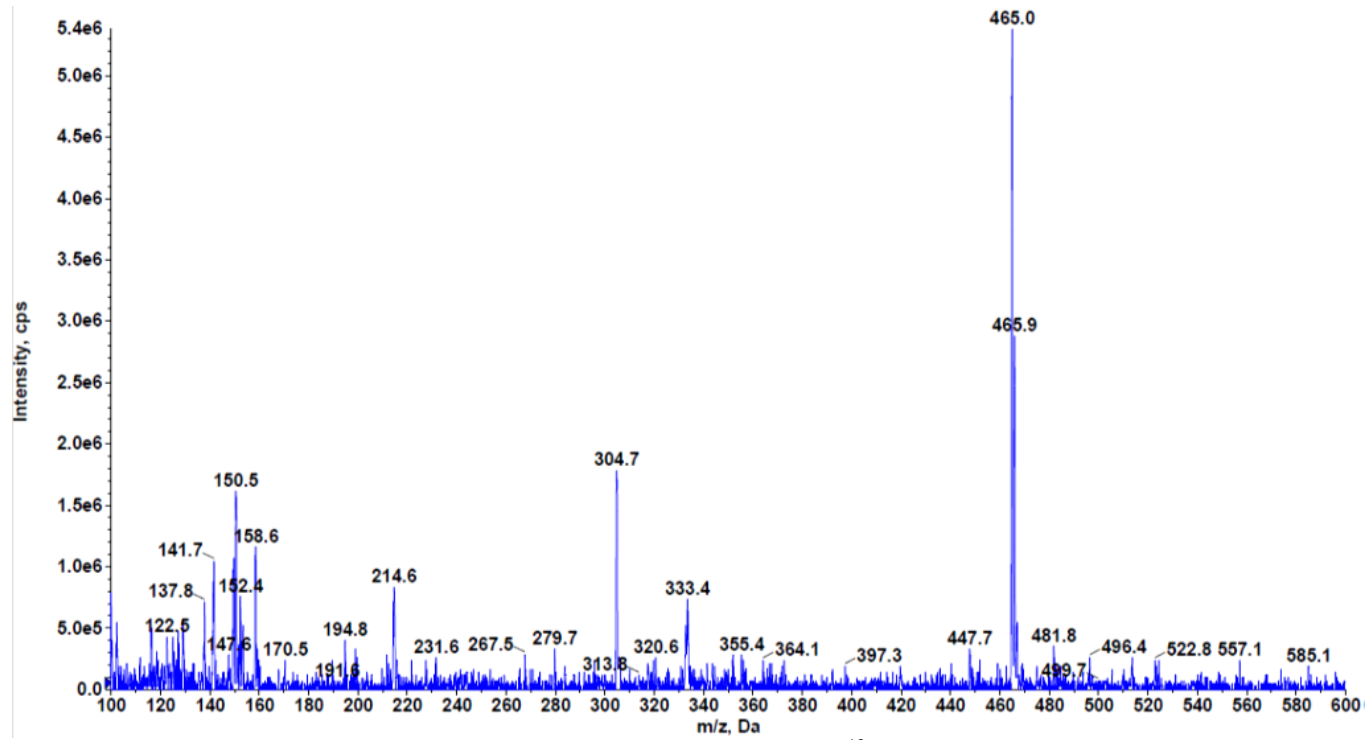

Fig. 2c: Mass spectra of Apixaban ${ }^{13} \mathrm{CD}_{3}$

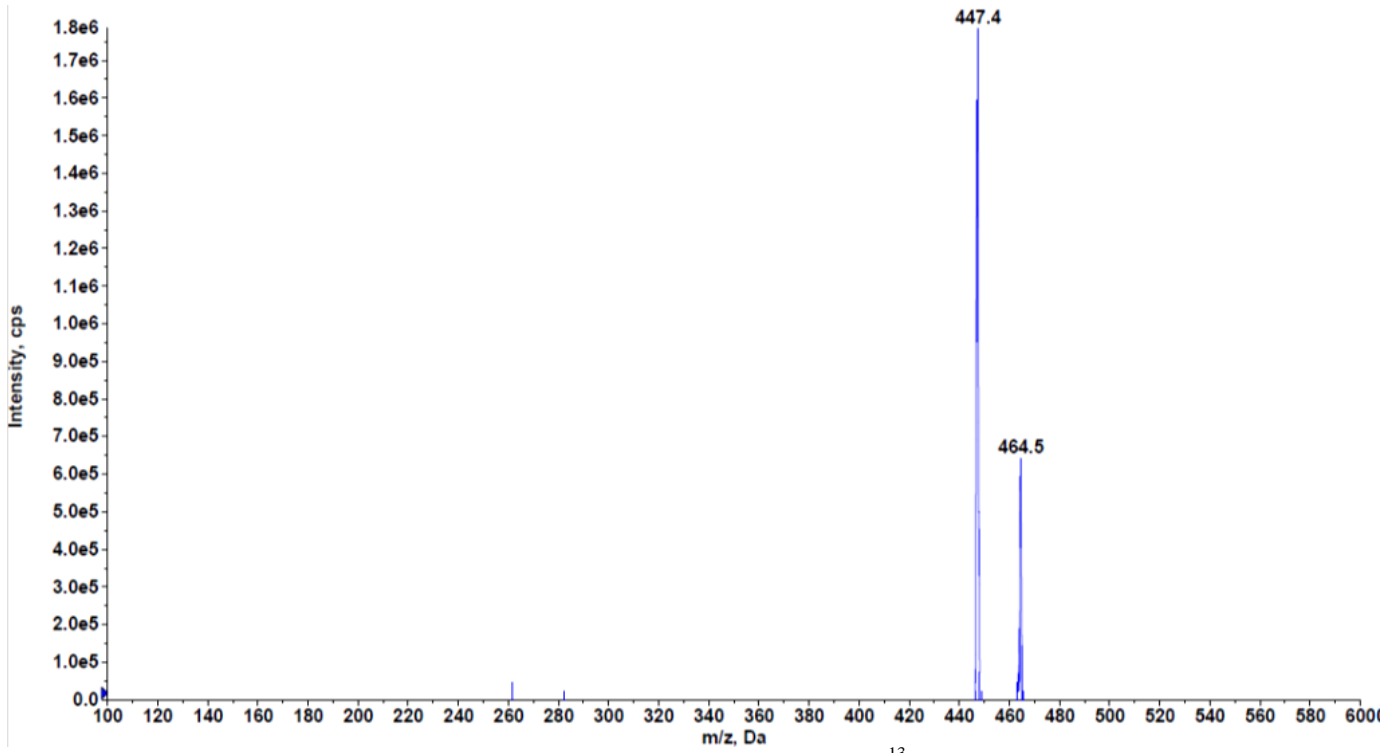

Fig. 2d: Product ion spectra of Apixaban ${ }^{13} \mathrm{CD}_{3}$. 


\section{Method Validation}

The HPLC-MS/MS method was validated in accordance with the Guidance for industry, Bioanalytical method validation, as specified by US FDA (US FDA., 2001). The potential presence of endogenous contaminating compounds that may interfere with the analytical assay was determined by analyzing blank human $\mathrm{K}_{2}$ EDTA plasma samples of ten different individual lots. Representative chromatogram of extracted blank plasma sample is given in (Fig. 3a, 3b). No significant interference from endogenous
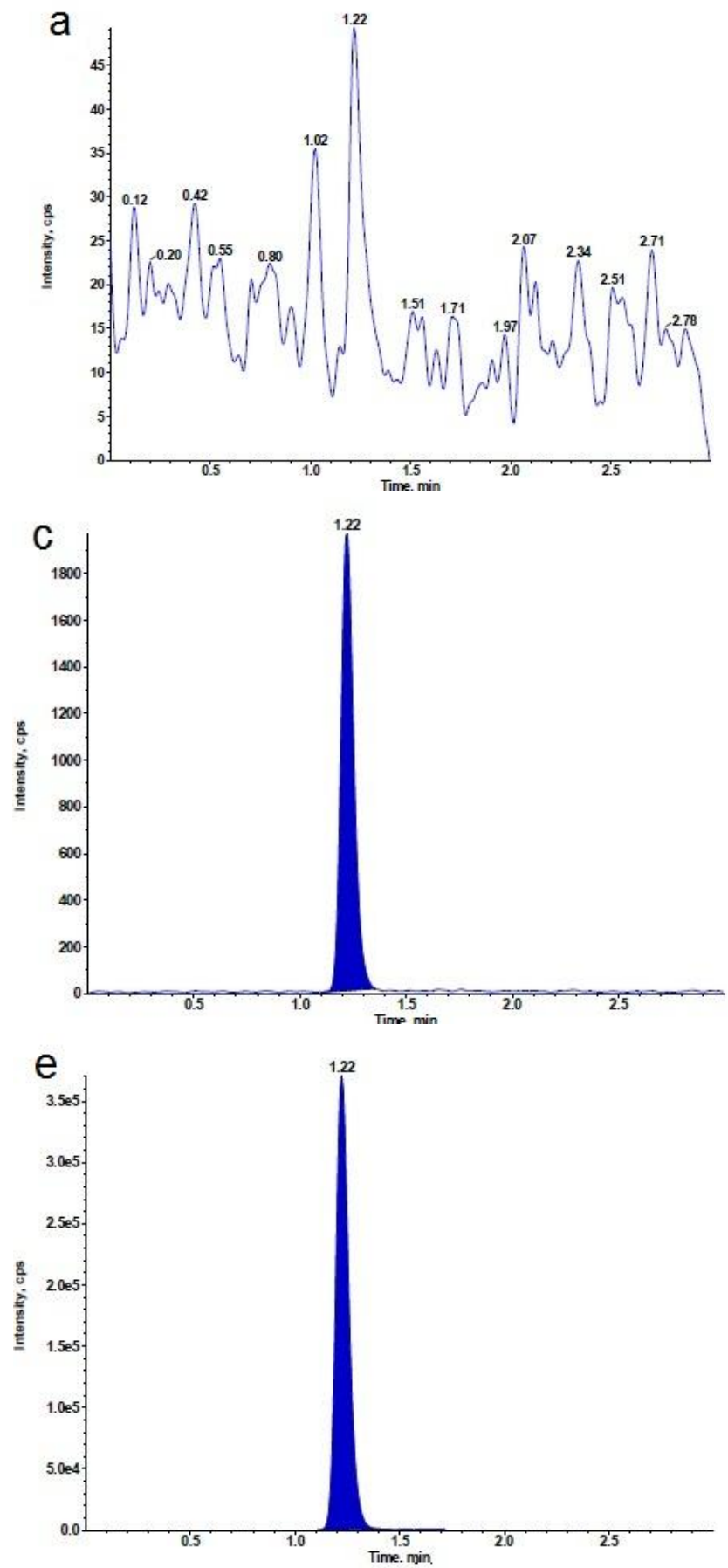

components was observed at retention time of analyte and IS in all the human plasma batches screened.

\section{Sensitivity}

The lowest limit of quantification (LLOQ) was set at the concentration of $1.0 \mathrm{ng} \mathrm{mL}^{-1}$ (Fig. 3c). Six replicates of blank plasma were spiked at a concentration of $1.0 \mathrm{ng} \mathrm{mL}$. The precision and accuracy at LLOQ were found to be $3.72 \%$ and $93.80 \%$ respectively.
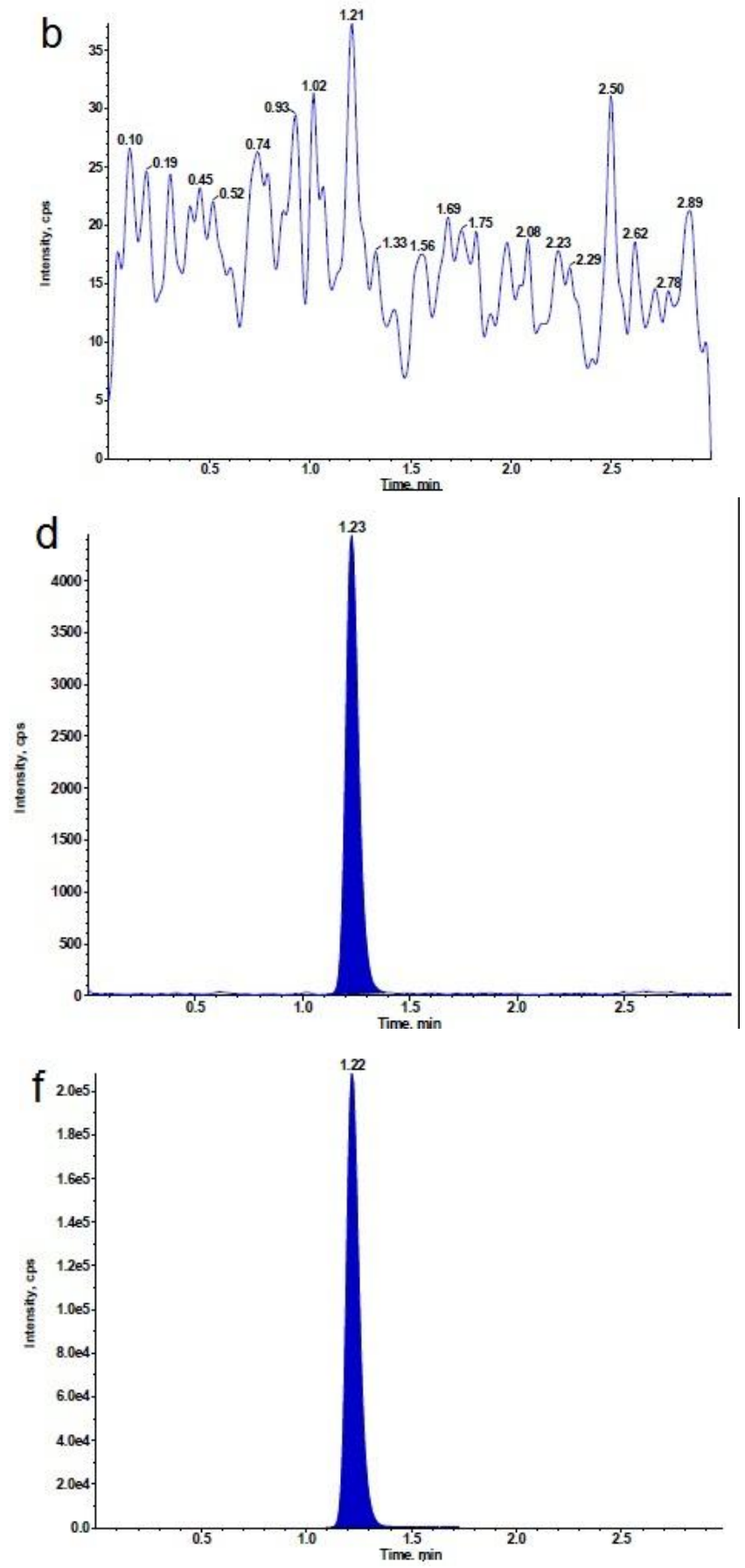

Fig. 3: Representative chromatograms a. Blank (Apixaban), b. Blank IS (Apixaban ${ }^{13} \mathrm{CD}_{3}$ ), c. Extracted LLOQ $1.0 \mathrm{ng} / \mathrm{mL}$, d. Extracted LQC $2.77 \mathrm{ng} / \mathrm{mL}$, e. Extracted HQC $246.31 \mathrm{ng} / \mathrm{mL}$, f. Extracted IS Apixaban ${ }^{13} \mathrm{CD}_{3}$. 


\section{Matrix Factor}

Ten different lot of blank plasma were taken, extracted as per extraction method described above and spiked with LQC and HQC equivalent aqueous concentrations after extraction, thus achieving unextracted samples. Responses of these unextracted samples were compared with spiked extracted LQC and HQC samples to calculate matrix factor. No significant matrix effect was observed at low and high concentration levels.

\section{Recovery}

The peak areas of extracted LQC, MQC and HQC samples of apixaban and peak areas of extracted MQC samples of IS apixaban ${ }^{13} \mathrm{CD}_{3}$ were compared against the peak areas of respective unextracted QC samples. The overall mean recovery of apixaban and IS apixaban ${ }^{13} \mathrm{CD}_{3}$ was found to be $98.53 \%$ and $101.18 \%$ respectively.

\section{RESULTS AND DISCUSSION}

\section{Linearity and Precision and Accuracy}

A regression equation with a weighting factor of $1 /$ (concentration $^{2}$ ) was judged to produce the best fit for the concentration-detector response relationship for apixaban in human plasma. The representative calibration curve for regression analysis is illustrated in (Fig. 4). Coefficient of determination $\left(r^{2}\right)$ was greater than 0.999 in the concentration range from $1.0 \mathrm{ng} \mathrm{mL}^{-1}$ to $301.52 \mathrm{ng} \mathrm{mL}^{-1}$ (Table 1).

The precision of the assay was measured by the percent coefficient of variation over the concentration range of LLOQ QC, LQC, M1QC, MQC and HQC samples respectively, during the course of validation. The accuracy of the assay was defined as the absolute value of the ratio of the calculated mean values of the LLOQ QC, LQC, M1QC, MQC and HQC samples to their respective nominal values, expressed in percentage (Fig. 3).Within batch precision ranged from $0.70 \%$ to $3.72 \%$ and the within batch accuracy ranged from $89.24 \%$ to $107.20 \%$. Intra-day precision ranged from $0.98 \%$ to $3.27 \%$ and the intra-day accuracy ranged from $89.60 \%$ to $94.30 \%$. Between batch/inter day precision ranged from $5.22 \%$ to $6.98 \%$ and the between batch /inter day accuracy ranged from $93.03 \%$ to $98.60 \%$ (Table 2a \& 2b).

\section{Stability Studies}

\section{Standard stock solution stability}

Room temperature stock solution stability of apixaban. The standard stock solution of apixaban was prepared. Stock solution was kept on the bench at room temperature for $24 \mathrm{hrs}$. Dilution was prepared from stock solution as stability stock and a fresh dilution was prepared as comparison stock. Room temperature stock solution stability of apixaban was carried out by injecting six replicates from the above prepared stock dilutions of apixaban at room temperature. The stability was found to be $100.56 \%$.

\section{Freeze-Thaw Stability}

The stability of apixaban in human plasma was determined during 3 freeze-thaw cycles. Six sets of QC (LQC \& HQC) samples were analyzed after FT-3 cycles. Six sets of freshly spiked QC (LQC \& HQC) samples were prepared on the day of experiment and injected along with the freeze-thaw QC samples and quantified against the freshly spiked CC standards.

The precision ranged from $1.53 \%$ to $2.62 \%$ and accuracy ranged from $100.97 \%$ to $102.09 \%$. The freshly spiked CC standards and QC samples were found within the acceptance criteria (Table 4).

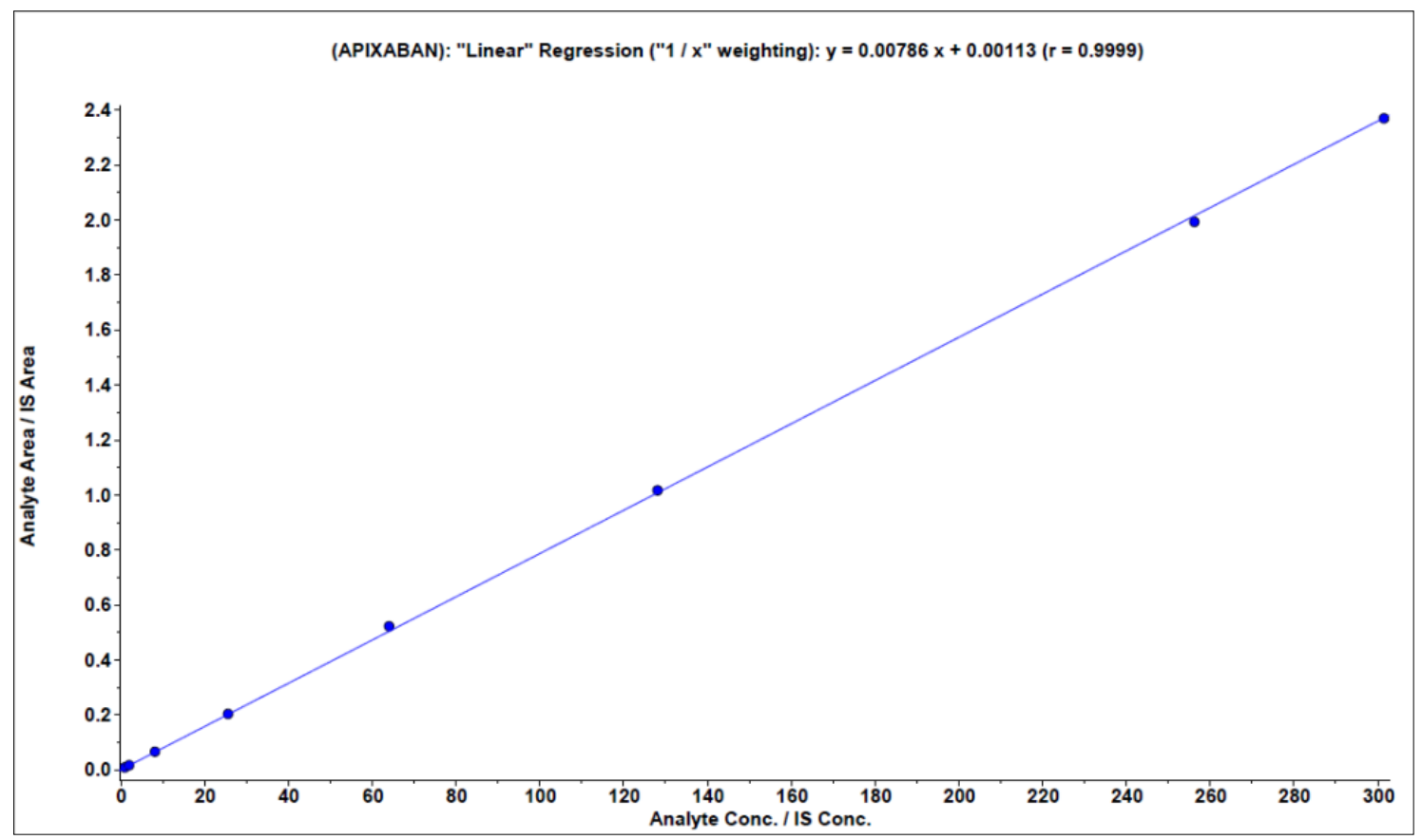

Fig. 4: Apixaban linearity curve over the range of $1.0 \mathrm{ng} / \mathrm{mL}$ to $301.52 \mathrm{ng} / \mathrm{mL}$ 
Table 1: Back calculated concentrations of calibrators for Apixaban.

\begin{tabular}{|c|c|c|c|}
\hline $\begin{array}{c}\text { Nominal Concentration of } \\
\text { Apixaban }\end{array}$ & $\begin{array}{l}\text { Back calculated concentration } \\
(\text { mean } \pm \text { SD }) n=3\end{array}$ & RSD $(\%)$ & Accuracy (\%) \\
\hline 1.00 & $0.993 \pm 0.0 .0058$ & 0.58 & 99.30 \\
\hline 2.00 & $2.033 \pm 0.0289$ & 1.42 & 101.65 \\
\hline 8.20 & $8.307 \pm 0.0751$ & 0.90 & 101.30 \\
\hline 25.63 & $25.543 \pm 0.0231$ & 0.09 & 99.66 \\
\hline 64.07 & $64.393 \pm 1.2573$ & 1.95 & 100.50 \\
\hline 128.15 & $128.153 \pm 0.6204$ & 0.48 & 100.00 \\
\hline 256.29 & $253.737 \pm 3.2080$ & 1.26 & 99.00 \\
\hline 301.52 & $298.070 \pm 0.7202$ & 0.24 & 98.86 \\
\hline
\end{tabular}

Table 2a: Within-batch accuracy (\% of nominal concentration) and precision (\% RSD) of Apixaban in human plasma.

\begin{tabular}{|c|c|c|c|}
\hline \multirow[t]{2}{*}{ QC i.d } & \multirow[t]{2}{*}{ QC Nominal Concentration $\left(\mathrm{ng} \mathrm{mL}^{-1}\right)$} & \multicolumn{2}{|c|}{ Within Batch $(n=6)$} \\
\hline & & Precision (RSD, \%) & Mean Accuracy (\%) \\
\hline LLOQ & 1.0 & 3.72 & 93.80 \\
\hline Low & 2.77 & 1.28 & 89.96 \\
\hline Medium1 & 61.58 & 1.06 & 92.45 \\
\hline Medium & 123.16 & 1.65 & 91.98 \\
\hline High & 246.31 & 0.77 & 91.73 \\
\hline
\end{tabular}

Table 2b: Within-day and between days accuracy (\% of nominal concentration) and precision (\% RSD) of Apixaban in human plasma.

\begin{tabular}{|c|c|c|c|c|c|}
\hline \multirow[t]{2}{*}{ QC i.d } & \multirow{2}{*}{$\begin{array}{c}\text { QC Nominal } \\
\text { Concentration }\left(\mathrm{ng} \mathrm{mL} \mathbf{m L}^{-1}\right)\end{array}$} & \multicolumn{2}{|c|}{ Within same day $(n=12)$} & \multicolumn{2}{|c|}{ Different days $(n=18)$} \\
\hline & & Precision (RSD, \%) & Mean Accuracy (\%) & Precision (RSD, \%) & Mean Accuracy (\%) \\
\hline LLOQ & 1.0 & 3.27 & 94.30 & 6.98 & 98.60 \\
\hline Low & 2.77 & 1.45 & 89.60 & 5.53 & 93.03 \\
\hline Medium1 & 61.58 & 0.98 & 92.04 & 5.47 & 95.57 \\
\hline Medium & 123.16 & 1.23 & 91.87 & 5.22 & 95.20 \\
\hline High & 246.31 & 1.07 & 91.54 & 5.24 & 94.90 \\
\hline
\end{tabular}

Table 3: Bench top and post preparative (auto injector) stability.

\begin{tabular}{|c|c|c|c|c|c|c|c|}
\hline \multirow{2}{*}{ QC i.d } & \multirow{2}{*}{ 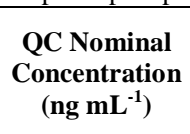 } & \multicolumn{3}{|c|}{$\begin{array}{l}\text { Stability after } 6 \mathrm{~h} \text { at room temperature } \\
\text { (Bench top stability, } n=6 \text { ) }\end{array}$} & \multicolumn{3}{|c|}{$\begin{array}{l}\text { Stability after } 53 \mathrm{~h} \text { at } 10^{\circ} \mathrm{C} \\
(\text { post preparative, } \mathrm{n}=6)\end{array}$} \\
\hline & & $\begin{array}{l}\text { Mean Concentration found } \\
\left.(\mathbf{n g ~ m L})^{-1}\right)\end{array}$ & $\begin{array}{l}\text { Precision } \\
\text { (RSD, \%) }\end{array}$ & $\begin{array}{c}\text { Mean } \\
\text { Accuracy }(\%)\end{array}$ & $\begin{array}{l}\text { Mean Concentration } \\
\text { found }\left(\mathrm{ng} \mathrm{mL} \mathbf{~ L}^{-1}\right)\end{array}$ & $\begin{array}{l}\text { Precision } \\
(\text { RSD, \%) }\end{array}$ & $\begin{array}{c}\text { Mean } \\
\text { Accuracy }(\%)\end{array}$ \\
\hline Low & 2.77 & 2.833 & 1.27 & 102.27 & 2.833 & 1.86 & 100.72 \\
\hline High & 246.31 & 249.252 & 1.23 & 101.19 & 249.252 & 0.92 & 101.01 \\
\hline
\end{tabular}

\section{Short Term Room Temperature (Bench top) Stability for 6 hrs}

Short-term room temperature stability was determined by using six sets of QC (LQC and HQC) samples at room temperature. Six sets of freshly spiked QC (LQC and HQC) samples were prepared on the day of experiment and injected along with the stability QC samples and quantified against the freshly spiked CC standards. Apixaban was found to be stable up to $6 \mathrm{hrs}$. The precision ranged from $1.23 \%$ to $1.27 \%$ and the accuracy ranged from $101.19 \%$ to $102.27 \%$ (Table 3 ).

\section{Auto sampler stability for 53 hrs}

In assessing the auto sampler stability, six sets of QC samples (LQC and HQC from PA Batch: 03) were processed and placed in the auto sampler. They were injected after a period of 53 hrs. Six sets of freshly spiked QC (LQC and HQC) samples were prepared on the day of experiment and injected along with the stability QC samples and quantified against the freshly spiked CC standards. The results demonstrate that the processed samples were stable up to $53 \mathrm{hrs}$. The precision ranged from $0.92 \%$ to 1.86 $\%$ and accuracy ranged from $100.72 \%$ to $101.01 \%$ (Table 3 ).

\section{Long Term Stability data (below $-50^{\circ} \mathrm{C}$ ) for 199 days}

The stability of apixaban, for plasma samples stored below $-50^{\circ} \mathrm{C}$ was generated for 199 days by quantifying six sets of QC samples (LQC and HQC). Six sets of freshly spiked QC (LQC and HQC) samples were prepared on the day of experiment and injected along with the stability QC samples and quantified against the freshly spiked CC standards. The precision of the calculated concentrations of QC samples ranged from $0.97 \%$ to $2.26 \%$ and accuracy ranged from $92.71 \%$ to $94.56 \%$. The freshly spiked CC standards and QC samples were found within the acceptance criteria (Table 4) 
Table 4: Long term and freeze thaw stability of Apixaban.

\begin{tabular}{|c|c|c|c|c|c|c|c|}
\hline \multirow[b]{2}{*}{ QC i.d } & \multirow{2}{*}{$\begin{array}{l}\text { QC Nominal } \\
\text { Concentration } \\
\left(\mathbf{n g ~ m L ^ { - 1 } )}\right.\end{array}$} & \multicolumn{3}{|c|}{ Stability after three freeze thaw cycles } & \multicolumn{3}{|c|}{$\begin{array}{l}\text { Long term stability of Apixaban at }-50^{\circ} \mathrm{C} \text { after } 156 \\
\text { days }\end{array}$} \\
\hline & & $\begin{array}{l}\text { Mean Concentration } \\
\text { found }\left(\mathrm{ng} \mathbf{~ m L}^{-1}\right)\end{array}$ & $\begin{array}{l}\text { Precision (RSD, } \\
\%)\end{array}$ & $\begin{array}{l}\text { Mean Accuracy } \\
(\%)\end{array}$ & $\begin{array}{c}\text { Mean } \\
\text { Concentration } \\
\text { found }\left(\mathrm{ng} \mathrm{mL} \mathrm{mL}^{-1}\right)\end{array}$ & $\begin{array}{l}\text { Precision } \\
(\text { RSD, \%) }\end{array}$ & $\begin{array}{c}\text { Mean } \\
\text { Accuracy }(\%)\end{array}$ \\
\hline Low & 2.77 & 2.797 & 2.62 & 100.97 & 2.568 & 2.26 & 92.71 \\
\hline High & 246.31 & 251.460 & 1.53 & 102.09 & 232.908 & 0.97 & 94.56 \\
\hline
\end{tabular}

Table 5: Table Dilution Integrity.

\begin{tabular}{|c|c|c|c|c|}
\hline Sample ID & $\begin{array}{c}\text { Nominal } \\
\text { Concentration }\left(\mathbf{n g} \mathrm{mL}^{-}\right. \\
\left.\mathbf{1}_{\mathbf{1}}\right)\end{array}$ & $\begin{array}{c}\text { Mean Back Calculated } \\
\text { Concentration } n=6 \\
\left(n g \mathbf{~ m L}^{-1}\right)\end{array}$ & Precision (RSD, \%) & Mean Accuracy (\%) \\
\hline 2xDilution & 513.15 & 499.620 & 0.94 & 97.36 \\
\hline 4xDilution & 513.15 & 508.703 & 0.79 & 99.13 \\
\hline
\end{tabular}

\section{Dilution Integrity}

Dilution integrity samples were prepared by spiking about 1.7 times the highest standard concentration of apixaban (301.52 $\mathrm{ng} \mathrm{mL} \mathrm{mL}^{-1}$ ). Six sets of dilution integrity samples were processed by diluting them twice and another six sets were processed by diluting them four times. These dilution QC samples were analyzed along with $\mathrm{CC}$ standards and were calculated using $2 \mathrm{x}$ and $4 \mathrm{x}$ dilution factor respectively. The precision and accuracy for a dilution factor of 2 was found to be $0.94 \%$ and $97.36 \%$ respectively. Similarly, the precision and accuracy for a dilution factor of 4 were found to be $0.79 \%$ and $99.13 \%$ respectively (Table 5).

\section{CONCLUSION}

In this study, we described a sensitive and selective high performance liquid chromatography-tandem mass spectrometry method for the analysis of apixaban in human plasma. Validation of the method in selected conditions shows that the method is selective and precise with linear response of mass spectrometer. The liquid-liquid extraction procedures produced clean chromatograms and high and reproducible recovery was obtained for investigated compound. The method has been found suitable to support pharmacokinetic studies.

\section{Financial support and sponsorship: Nil.}

Declaration of conflict of interest: The authors report no conflicts of interest. The authors alone are responsible for the content and writing of the paper.

\section{REFERENCES}

Baldelli S, Cattaneo D, Pignatelli P, Perrone V, Pastori D, Radice S, Violi F, Clementi E. Validation of an LC-MS/MS method for the simultaneous quantification of dabigatran, rivaroxaban and apixaban in human plasma. Bioanalysis, 2016; 8(4): 275-83.

Barrett YC, Wang Z, Frost C, Shenker A. Clinical laboratory measurement of direct factor Xa inhibitors: anti-Xa assay is preferable to prothrombin time assay. Thromb. Haemost, 2010; 104(6): 1263-71.
Blaich C, Müller C, Michels G, Wiesen MH. Multi-analyte analysis of non-Vitamin $\mathrm{K}$ antagonist oral anticoagulants in human plasma using tandem mass spectrometry. Clin. Chem. Lab. Med, 2015; 53(12): 1981-90.

Delavenne X, Mismetti P, Basset T. Rapid determination of apixaban concentration in human plasma by liquid chromatography /tandem mass spectrometry: application to pharmacokinetic study. J. Pharm. Biomed. Anal, 2013; 78-79: 150-53.

Gadisseur AP, Kaptein AA, Breukink-Engbers WG, van der Meer FJ, Rosendaal FR. Patient self-management of oral anticoagulant care vs management by specialized anticoagulation clinics: positive effects on quality of life. J. Thromb. Haemost, 2004; 2(4): 584-591.

Gous T, Couchman L, Patel JP, Paradzai C, Arya R, Flanagan RJ. Measurement of the direct oral anticoagulants apixaban, dabigatran, edoxaban, and rivaroxaban in human plasma using turbulent flow liquid chromatography with high-resolution mass spectrometry. Ther. Drug Monit, 2014; 36(5):597-605.

Matchar DB, Samsa GP, Cohen SJ, Oddone EZ, Jurgelski AE. Improving the quality of anticoagulation of patients with atrial fibrillation in managed care organizations: results of the managing anticoagulation services trial. Am. J. Med, 2002; 113(1): 42-51.

Mueck W, Lensing AW, Agnelli G, Decousus H, Prandoni P, Misselwitz F. Rivaroxaban. population pharmacokinetic analyses in patients treated for acute deep-vein thrombosis and exposure simulations in patients with atrial fibrillation treated for stroke prevention. Clin. Pharmacokinet, 2011; 50(10): 675-86.

Mueck W, Schwers S, Stampfuss J. Rivaroxaban and other novel oral anticoagulants: pharmacokinetics in healthy subjects, specific patient populations and relevance of coagulation monitoring. Thromb. J, 2013; 11(1): 10.

Noguez JH, Ritchie JC. Quantitation of the Oral Anticoagulants Dabigatran, Rivaroxaban, Apixaban, and Warfarin in Plasma Using Ultra-Performance Liquid Chromatography with Tandem Mass Spectrometry (UPLC-MS/MS). Methods Mol. Bio, 2016; 1383: 21-27.

Schmitz EM, Boonen K, van den Heuvel DJ, van Dongen JL, Schellings MW, Emmen JM, van der Graaf F, Brunsveld L, van de Kerkhof D. Determination of dabigatran, rivaroxaban and apixaban by ultra-performance liquid chromatography-tandem mass spectrometry (UPLC-MS/MS) and coagulation assays for therapy monitoring of novel direct oral anticoagulants. J. Thromb. Haemost, 2014; 12(10): 1636-46.

Shenker A, Wang J, Pursley J, Boyd RA, Lacreta F, Frost C. Apixaban pharmacokinetics and pharmacodynamics in subjects with renal impairment. In: Presented at: Annual Meeting of the American College of Clinical Pharmacology; September 23-25, 2012; San Diego. Clin. Pharmacol. Drug Dev, 2012; 1(4): 175-229.

U.S. Food and Drug Administration. Bioanalytical Method Validation, Guidance for Industry. U.S. department of Health and Human Services Food and Drug Administration, Rockville, MD. https://www.fda.gov/downloads/Drugs/Guidance/ucm070107.pdf 
Wang L, Zhang D, Raghavan N, et al. In vitro assessment of metabolic drug-drug interaction potential of apixaban through cytochrome P450 phenotyping, inhibition, and induction studies. Drug Metab. Dispos, 2010; 38(3): 448-58.

Wang L, Zhang D, Swaminathan A, Xue Y, Cheng PT, Wu S, Mosqueda-Garcia R, Aurang C, Everett DW, Humphreys WG. Glucuronidation as a major metabolic clearance pathway of ${ }^{[14 C]}$ muraglitazar in humans: metabolic profiles in subjects with or without bile collection. Drug Metab. Dispos, 2006; 34(3): 427-39.

Zhang WL, Lou D, Zhang DT, Zhang Y, Huang HJ. Determination of rivaroxaban, apixaban and edoxaban in rat plasma by UPLC-MS/MS method. J. Thromb. Thrombolysis, 2016; 42(2): 205-11.

\section{How to cite this article:}

Baig MLA, Ali SA. A Validated LC-MS/MS Method for the Estimation of Apixaban in Human Plasma. J App Pharm Sci, 2017; 7 (04): 044-052. 